\title{
Effect of inulin polymerization degree on various properties of synbiotic fermented milk including Lactobacillus acidophilus La-5 and Bifidobacterium animalis Bb-12
}

\author{
Sebnem Ozturkoglu-Budak, ${ }^{*}$ H. Ceren Akal, İlkay Buran, and Atila Yetişemiyen \\ Department of Dairy Technology, Faculty of Agriculture, Ankara University, 06110 Ankara, Turkey
}

\section{ABSTRACT}

The effects of inulin degree of polymerization (DP) on the viabilities of Lactobacillus acidophilus $\mathrm{La}-5$ and $\mathrm{Bi}$ fidobacterium animalis $\mathrm{Bb}-12$ and on some parameters of fermented milk, such as microbiological, rheological, biochemical, and sensory properties, were investigated during $30 \mathrm{~d}$ of storage. Samples were produced using L. acidophilus La-5 and B. animalis $\mathrm{Bb}-12$, along with inulin having different DP as prebiotic, and the effects of high-DP (DP $\geq 23)$ and low-DP $(\mathrm{DP} \leq 10)$ inulin on fermented milk, were determined. The viability of both strains increased when they were used with inulin having any DP. The addition of inulin increased the consistency index of all samples. During storage, we observed an increase in lactic and acetic acid contents of samples in which high-DP inulin was used, for both strains of bacteria. Of the combinations we tested, the sample produced with L acidophilus La-5 and high-DP inulin demonstrated the highest rheological and sensory performance as well as the best viability of probiotics. Key words: synbiotic, inulin, polymerization degree, L. acidophilus La-5, B. animalis Bb-12

\section{INTRODUCTION}

Probiotic bacteria are described as "living microorganisms that provide a health benefit to the consumer after consumption" (FAO/WHO, 2006). Probiotic supplementation of food has grown increasingly popular in recent years (Ong et al., 2007). The potential benefits of probiotic bacteria include reduction in cholesterol, enhancement in immunity, relief of the negative effects of lactose intolerance, treatment of some intestinal disorders such as diarrhea, and decreased risk of some illnesses, including cancer (Shah, 2000a; Shah and Ravula, 2000). For these reasons, foods containing probi-

Received February 13, 2019.

Accepted March 23, 2019.

*Corresponding author: budak@ankara.edu.tr otics are categorized as "functional foods" (Ong et al., 2006). Dairy foods, especially yogurt, kefir, cheese, and fermented milk, are the most frequently supplemented with probiotics (Oliveira et al., 2017). Lactobacillus acidophilus and Bifidobacterium animalis are the main probiotic bacteria used in the dairy industry (Saxelin et al., 2005). Inclusion of these microorganisms can yield fermented or non-fermented probiotic milks.

Prebiotics are non-digestible food components used by probiotics, which provide health benefits to the host (FAO/AGNS, 2007). Probiotics are often used in integration with prebiotics, in what are called synbiotic products. Also, prebiotic ingredients can be used as dietary fiber for the enhancement of various properties in foodstuffs. The prebiotics in synbiotic foods may improve the survival, viability, and permanency of consumed probiotics in the gastrointestinal system, by selectively encouraging their growth and promoting their metabolism (Gibson and Roberfroid, 1995; Gibson et al., 2010; Bogovič Matijašić et al., 2016). In the dairy industry, use of prebiotics has gained importance not only due to their health benefits but also due to their technological advantages (Guimarães et al., 2018).

Inulin is among the principal prebiotics used in the dairy industry. Inulin is a water-soluble and fermentable fiber originating from several plants. It is a linear polysaccharide that consists of fructose molecules linked by $\beta-2-1$ bonds with a terminal glucose unit (Paseephol et al., 2008; Rezaei et al., 2014). Although the main role of inulin is to stimulate the growth of probiotic bacteria, it has also various technological features that are valued in the food industry, such as water holding capacity and texturizing ability (Kip et al., 2006). It is also reported to significantly increase the viscosity and shear thinning behavior in ice cream (Soukoulis et al., 2009). Inulin is produced with diversified degrees of polymerization (DP). It can be categorized into 3 groups according to DP value: short-chain $(\mathrm{DP}<10)$, medium-chain (DP 2-60), and long-chain (DP > 23; Luo et al., 2017a,b). Short-chain inulin is reported to have better water holding capacity than long-chain 
Table 1. Probiotic strain and prebiotic used for the production of synbiotic fermented milk samples

\begin{tabular}{lll}
\hline Sample code & Probiotic bacteria & Prebiotic \\
\hline C-LA (control) & Lactobacillus acidophilus La-5 & - \\
LPLA & L. acidophilus La-5 & Low-DP inulin ${ }^{1}$ \\
HPLA & L. acidophilus La-5 & High-DP inulin \\
C-BA (control) & Bifidobacterium animalis Bb-12 & - \\
LPBA & B. animalis Bb-12 & Low-DP inulin \\
HPBA & B. animalis Bb-12 & High-DP inulin \\
\hline
\end{tabular}

${ }^{1} \mathrm{DP}=$ degree of polymerization.

inulin; however, long-chain inulin shows higher viscosity and superior gel structure, even when used at low concentrations (Meyer et al., 2011; Luo et al., 2017a). Thus, to improve the nutritional, textural, stabilization/emulsification, or gel-forming properties of products, either type of inulin may be chosen based on the preferred feature (Meyer et al., 2011; Silva et al., 2015). Inulin is also used as a fat replacer, providing a creamlike taste (Shoaib et al., 2016; Guimarães et al., 2018). The DP value of inulin has also been found to affect its prebiotic properties (Mueller et al., 2015). In recent years, the effects of inulin DP value have been investigated in various food products, such as probiotic white (Konar et al., 2018) and dark chocolate (Konar et al., 2017), whey beverages (Guimarães et al., 2018), wheat starch (Luo et al., 2017a), and steamed bread (Luo et al., 2017b). However, as to best of our knowledge, there has been no study on the effects of inulin DP values in synbiotic fermented milk.

The aim of this study was to assess the effects of inulin DP on the physicochemical, microbiological, rheological, and sensory features of synbiotic fermented milks produced with $L$. acidophilus La-5 or B. animalis $\mathrm{Bb}-12$, as well as on the viability of these bacteria.

\section{MATERIALS AND METHODS}

\section{Materials}

Inulins with 2 different DP values were supplied by Beneo (Mannheim, Germany) for this study. Orafti HSI-t $(\mathrm{DP}<10)$ and Orafti HPX (DP > 23) were used as low- and high-DP inulin, respectively.

\section{Probiotic Cultures and Inoculum Preparation}

Commercial freeze-dried cultures of $L$. acidophilus La-5 and B. animalis Bb-12 (Chr. Hansen, Hørsholm, Denmark) were used in this study. Both strains were weighted individually in sufficient amounts to acquire an inoculation level of $10^{8} \mathrm{cfu} / \mathrm{mL}$ in fermented milk, calculated according to the initial microbial counts of cultures from the manufacturer's instructions. Suspen- sions were obtained by dissolving each culture in 25 $\mathrm{mL}$ of sterile skim milk $\left(108^{\circ} \mathrm{C}\right.$ for $\left.20 \mathrm{~min}\right)$ and were activated at $37^{\circ} \mathrm{C}$ for 40 min before use.

\section{Fermented Milk Production}

Raw bovine milk was obtained from the Dairy Technology Department of Ankara University (Ankara, Turkey) and preheated to $50^{\circ} \mathrm{C}$ for the addition of inulin. The batch was divided into 3 portions: 2 portions were supplemented with 2 different kinds of inulin (DP $\leq 10$ and $\mathrm{DP} \geq 23$ ) individually, at a ratio of $2 \%$ (wt/vol), and the last portion was used as a control sample with no added inulin. Following this step, all milk portions were heat-treated at $90^{\circ} \mathrm{C}$ for $5 \mathrm{~min}$ and subsequently cooled to $37^{\circ} \mathrm{C}$. Then each portion was aseptically divided in 2 , and one of the divided parts was inoculated with $L$. acidophilus La-5, while the other was inoculated with $B$. animalis $\mathrm{Bb}-12$. In the end, 6 different samples were obtained, as shown in Table 1.

Incubation of the samples was carried out at $37^{\circ} \mathrm{C}$ until the $\mathrm{pH}$ reached 4.6. At that point, fermentation was ceased by rapid cooling to $4^{\circ} \mathrm{C}$. In total, $18 \mathrm{~kg}$ of fermented milk was produced in each repetition. All productions were made in duplicate, and each sample was stored at $4^{\circ} \mathrm{C}$. Analyses were performed on d 1, 15, and 30 .

\section{Chemical Analyses}

The $\mathrm{pH}$ of the samples was measured using a $\mathrm{pH}$ meter (MP225, Mettler-Toledo, Columbus, $\mathrm{OH}$ ) fitted with a combined electrode. The titratable acidity of the samples was defined according to the method reported by Bradley et al. (1993) and calculated in lactic acid percentage. Total protein was analyzed using the Kjeldahl method (IDF, 1993), with a Büchi K435 digestion system and Büchi 323 distillation unit (Büchi Labortechnik AG, Flawil, Switzerland). To convert nitrogen percentage to protein percentage, values were multiplied by a factor of 6.38 . Total solids were determined according to AOAC International (2006; method no. 990.19), and fat content was analyzed using the 
Gerber method (AOAC International, 2006; method no. 2000.18). All analyses were performed in duplicate.

\section{Microbiological Analyses}

To determine probiotic viability, L. acidophilus La-5 and $B$. animalis $\mathrm{Bb}-12$ were enumerated. For each probiotic, 10-g samples were mixed with $90 \mathrm{~mL}$ of Ringer solution in Stomacher Bags (Seward Ltd., Worthing, UK; Bag Mixer 400, Interscience, St.-Nom-La-Bretèche, France), homogenized for $2 \mathrm{~min}$, and subjected to serial dilutions in Ringer solution (Merck, Darmstadt, Germany). Enumerations were performed according to the pour-plate technique.

Lactobacillus acidophilus La-5 was enumerated on de Man, Rogosa, and Sharpe (MRS) sorbitol agar with sorbitol substituted for glucose (10 g/L, Merck) after an anaerobic incubation at $37^{\circ} \mathrm{C}$ for $72 \mathrm{~h}$ (Oberg et al., 2011). Bifidobacterium animalis Bb-12 populations were counted on MRS agar (Merck) containing NNPL (neomycin sulfate $100 \mathrm{mg} / \mathrm{L}$, nalidixic acid 15 $\mathrm{mg} / \mathrm{L}$, paromomycin sulfate $200 \mathrm{mg} / \mathrm{L}$, lithium chloride $3 \mathrm{mg} / \mathrm{L}$, and L-cysteine chloride $0.5 \mathrm{mg} / \mathrm{L}$; SigmaAldrich, St. Louis, MO) and incubated at $37^{\circ} \mathrm{C}$ for 72 $\mathrm{h}$ under anaerobic conditions (Ong et al., 2006). All bacterial analyses were conducted in duplicate. The colonies formed in plates were enumerated, and cell concentration was given in $\log \mathrm{cfu} / \mathrm{mL}$.

\section{Volatile Flavor Compound Analyses}

Volatile flavor compounds were analyzed by headspace technique according to the method of Ulberth (1991) with minor modifications. Analyses were carried out with a gas chromatograph system (6890 series GC, Agilent Technologies, Santa Clara, CA) equipped with a flame ionization detector and a polyethylene glycol capillary column (HP-Innowax, $30 \mathrm{~m} \times 320 \mu \mathrm{m} \times 0.25$ $\mu \mathrm{m}$ film thickness, Agilent Technologies). For each combination of pre- and probiotics, as well as for the probiotic-only controls, a 5-g sample was weighed into a 20-mL headspace vial and capped with a crimper. Before injection, vials were held at $80^{\circ} \mathrm{C}$ for $20 \mathrm{~min}$ in a dry block heater (Thermo Fisher Scientific, Waltham, MA) for equilibrium of volatile compounds in the headspace. Subsequently, 1,000 $\mu \mathrm{L}$ of air from the top of each sample was removed from the vial with a gas-tight syringe and injected to the GC. All injections were performed in duplicate.

The operating parameters of the GC for volatile flavor compound detection were as follows: Inlet temperature of the $\mathrm{GC}$ was $80^{\circ} \mathrm{C}$, and the flame ionization detector temperature was $260^{\circ} \mathrm{C}$. Flow rates for make- up gas, hydrogen, and air were 30, 40, and $400 \mathrm{~mL} /$ min, respectively. Helium was used as a carrier gas, with a flow rate of $0.7 \mathrm{~mL} / \mathrm{min}$. The oven temperature was set to $80^{\circ} \mathrm{C}$ for $1 \mathrm{~min}$ at the beginning, then raised at $5^{\circ} \mathrm{C}$ per min to $170^{\circ} \mathrm{C}$ and held for $1 \mathrm{~min}$, and then increased to a final temperature of $210^{\circ} \mathrm{C}$ at a rate of $10^{\circ} \mathrm{C}$ per min, giving a run time of 24 min. Calibration solutions at concentrations of $10,25,50,75$, and 100 $\mathrm{mg} / \mathrm{L}$ were used for the quantitative calculation of each flavor compound.

\section{Organic Acid Analyses}

Lactic and acetic acids were analyzed according to the modified methods of Shah and Ravula (2000), Donkor et al. (2006), and Batista et al. (2015). Fermented milk samples of $3 \mathrm{~mL}$ each were mixed with $50 \mu \mathrm{L}$ of nitric acid $(15.5 \mathrm{M})$ and $1.0 \mathrm{~mL}$ of sulfuric acid (0.01 $M)$, which is used as mobile phase. The resulting mixture was centrifuged at $14,000 \times g$ for $30 \mathrm{~min}$ (Sigma 3-18KHS, Sartorius AG, Goettingen, Germany) to remove the proteins, and the supernatant was filtered through $0.22-\mu \mathrm{m}$ membrane filters (Milex, Millipore, Bedford, MA) before injection into the HPLC (1100 HPLC System, Agilent). All samples were analyzed in duplicate.

The separation and quantification of organic acids was performed using an HPLC system equipped with a UV detector, at $220 \mathrm{~nm}$, and an ion exchange column (Aminex HPX-87H, $300 \times 7.8 \mathrm{~mm}$; BioRad, Hercules, $\mathrm{CA}$ ) at a temperature of $65^{\circ} \mathrm{C}$. Isocratic separation was conducted with a mobile phase of $0.01 \mathrm{M} \mathrm{H}_{2} \mathrm{SO}_{4}$ with a flow rate of $0.6 \mathrm{~mL} / \mathrm{min}$, and the sample injection volume was $25 \mu \mathrm{L}$. Quantification of lactic and acetic acids was carried out according to the external standard method, using standard solutions of lactic and acetic acids (Sigma-Aldrich).

\section{Color Measurement}

The color characteristics of the samples were determined with Precise Color Reader TCR 200 (Time Group Inc., Beijing, China). Data on sample colors were obtained using the CIE $\mathrm{L}^{*} \mathrm{a}{ }^{*} \mathrm{~b}^{*}$ optical system ( $\mathrm{L}^{*}$ : lightness; $\mathrm{a}^{*}: \pm$ red-green; and $\mathrm{b}^{*}: \pm$ yellow-blue).

\section{Dynamic Rheological Test}

Fermented milk samples were gently stirred 10 times before rheological analysis. Steady shear viscometry was performed in duplicate at $5^{\circ} \mathrm{C}$, using a stainlesssteel $4^{\circ}$ conical geometry and a $2-\mathrm{mm}$ gap in a Kinexus Pro+ rheometer (Malvern Panalytical, Malvern, UK). 
Subsequent to an equilibrium time of $10 \mathrm{~s}$, shear stress was measured at 36 logarithmically separated shear rates over the range of 0.1 to $300 \mathrm{~s}^{-1}$. The flow curves obtained from viscometry were calculated according to the power law model, using nonlinear regression; the highest $R^{2}$ (0.9226 to 0.9907$)$ values were given by the following model:

$$
\sigma=K \cdot \gamma^{n},
$$

where $\sigma$ indicates shear stress, $K$ is the consistency index, $\gamma$ is the shear rate, and $n$ is the flow behavior index.

\section{Sensory Analysis}

Sensory evaluation of the fermented milk samples was performed by 7 trained panelists from the Department of Dairy Technology, Ankara University, according to the scoring system described by Bodyfelt et al. (1988). Fermented milks were evaluated on d 1, 15, and 30. Panelists evaluated the color/appearance, body/ texture, and odor/flavor, and noted any perceived defects in sensory attributes. Mean scores were calculated to compare the samples. The samples were randomly coded with 3 -digit numbers and served at 7 to $10^{\circ} \mathrm{C}$.

\section{Statistical Analyses}

A randomized complete block design was applied for 6 treatments, 3 storage periods, and 2 trials, to analyze the variables relating to the characteristics of fermented milk. To determine the significant differences between the evaluated responses, ANOVA general linear model procedure of Minitab statistical package (version 15.0, Minitab Inc., State College, PA) was carried out. Tukey's multiple comparison test was used to compare the treatment means and to determine whether there was any significant difference $(P<0.05)$ between treatments.

\section{RESULTS AND DISCUSSION}

\section{Chemical Parameters}

Table 2 shows the physicochemical properties of fermented milk samples. Inulin-added fermented milks had lower $\mathrm{pH}$ and higher titratable acidity than the control samples. These findings are in agreement with Aryana et al. (2007), Oliveira et al. (2009a), and Rezaei et al. (2014), who reported higher acidity and lower $\mathrm{pH}$ values in fermented milk or yogurt produced with the addition of inulin. In terms of $\mathrm{pH}$-decreasing effect of inulin addition, no significant differences $(P>0.05)$ were observed between the types of inulin (low- or highDP inulin) in fermented milks produced with either $L$. acidophilus La-5 or B. animalis $\mathrm{Bb}-12$. In other words, depending on their metabolism of inulin, the employed probiotic strains were not able to be used as indicators of the increase in titratable acidity and decrease in $\mathrm{pH}$. However, in contrast to our findings, Aryana et al. (2007) observed the lowest $\mathrm{pH}$ and highest acidity in yogurt with L. acidophilus incorporated with shortchain inulin.

During the 30-d storage period, a decrease in $\mathrm{pH}$ was observed in all evaluated fermented milk samples. We found that until d 15 of storage, $\mathrm{pH}$ values decreased, but after that a slight increase was observed until the end of storage. The successive decrease and increase in $\mathrm{pH}$ was paralleled by variation in titratable acidity values, as a result of the level of bacterial activity during the storage period. Regardless of the treatment, the acidities of fermented milk samples increased during the first $15 \mathrm{~d}$ of storage and reached stable average values after $30 \mathrm{~d}$ of storage. Statistically significant differences in titratable acidity values between treatments and among storage periods are shown in Table 2. The reason for the acidity stabilization at the end of the storage period in this study could be the decrease in lactic bacterial numbers and the consumption of residual lactose in substrates by $L$. acidophilus and $B$. animalis. Similar findings were reported by Bedani et al. (2013), Shah et al. (2016), and Akin and Ozcan (2017), in fermented milk and some other kinds of fermented dairy beverages. When low- and high-DP inulin were compared, the acidity values remained almost constant during the storage period.

The addition of either type of inulin as prebiotic caused an increase in the TS of fermented milks compared with control samples $(P<0.05)$. However, the TS of synbiotic samples produced with inulin having low or high DP were not different from one another $(P$ $>0.05)$. The increase in TS contents, compared with the non-synbiotic controls, are similar to those found by Cardarelli et al. (2008) and Oliveira et al. (2011) in different kinds of probiotic products, such as functional chocolate mousse and fermented skim milk.

No significant differences were observed in the fat content of samples, either in terms of different treatments or in terms of storage times $(P>0.05)$. Likewise, the protein content of all samples showed similar results across treatments and storage times $(P>0.05)$. These data are similar to those determined by Chaves and Gigante (2016), who reported that the addition of L. acidophilus La-5 or B. animalis Bb-12 did not affect the physicochemical composition of cheeses, such 
as TS, protein content, and fat content, compared with control samples. Moreover, we observed no correlation between the type of inulin and the TS, protein content, or fat content of our samples.

\section{Probiotic Bacteria Count}

The viable cell counts of $L$. acidophilus La-5 and $B$. animalis $\mathrm{Bb}-12$, obtained from all productions of fermented milk, are shown in Table 3. Populations of $L$. acidophilus and $B$. animalis in fermented milk samples were determined to be above $8 \log$ and $7 \log \mathrm{cfu} / \mathrm{mL}$, respectively, from production until the end of the storage period. This result accords with the standard for probiotic products, in which the minimum acceptable level of probiotics in dairy products to confer health benefits was determined to be $7 \mathrm{log} \mathrm{cfu} / \mathrm{mL}$ (Boylston et al., 2004). The National Yogurt Association of the United States indicates that probiotic yogurts must contain $8 \log \mathrm{cfu} / \mathrm{g}$ of lactic acid bacteria at the time of production (Pandey et al., 2017). Batista et al. (2015) also observed high microbial counts $(8 \log \mathrm{cfu} / \mathrm{mL})$ in yogurt produced with the addition of $L$. acidophilus and Bifidobacterium spp. Oliveira et al. (2011) reported that probiotic cell counts and their stabilities in fermented milk were influenced by culture types and composition. In the current study, viable cell counts increased during the first $15 \mathrm{~d}$ of storage, and a slight decrease was

Table 2. Physicochemical characteristics of fermented milks produced with probiotic bacteria and by using inulin with different degree of polymerization (DP) values at 1,15 , and $30 \mathrm{~d}$ of storage (mean $\pm \mathrm{SE} ; \mathrm{n}=2$ )

\begin{tabular}{|c|c|c|c|c|}
\hline Item & Sample $^{1}$ & d 1 & d 15 & d 30 \\
\hline \multicolumn{5}{|l|}{$\mathrm{pH}$ value } \\
\hline & C-LA & $4.79 \pm 0.020$ & $4.57 \pm 0.105$ & $4.66 \pm 0.015$ \\
\hline & LPLA & $4.60 \pm 0.005$ & $4.39 \pm 0.025$ & $4.42 \pm 0.025$ \\
\hline & HPLA & $4.57 \pm 0.000$ & $4.48 \pm 0.050$ & $4.51 \pm 0.125$ \\
\hline & C-BA & $4.70 \pm 0.190$ & $4.63 \pm 0.110$ & $4.63 \pm 0.265$ \\
\hline & LPBA & $4.57 \pm 0.015$ & $4.45 \pm 0.195$ & $4.51 \pm 0.075$ \\
\hline \multirow{2}{*}{\multicolumn{5}{|c|}{ Titratable acidity $\left({ }^{\circ} \mathrm{SH}\right)^{2}$}} \\
\hline & C-LA & $27.92+0.010^{\mathrm{bc}, \mathrm{B}}$ & $31.40+1.000^{\mathrm{A}}$ & $31.68+1.040^{\mathrm{A}}$ \\
\hline & LPLA & $33.20 \pm 0.080^{\mathrm{a}}$ & $36.30 \pm 1.900$ & $36.32 \pm 0.640$ \\
\hline & HPLA & $31.60 \pm 0.080^{\mathrm{abc}}$ & $33.20 \pm 0.200$ & $32.76 \pm 0.080$ \\
\hline & $\mathrm{C}-\mathrm{BA}$ & $28.24 \pm 0.465^{\mathrm{c}}$ & $30.30 \pm 0.220$ & $30.01 \pm 0.910$ \\
\hline & LPBA & $29.52 \pm 1.335^{\mathrm{bc}}$ & $33.58 \pm 3.820$ & $32.74 \pm 0.020$ \\
\hline & HPBA & $31.20 \pm 0.680^{\mathrm{ab}}$ & $33.04 \pm 0.240$ & $33.64 \pm 0.655$ \\
\hline \multicolumn{5}{|l|}{ Total solids (\% wt/wt) } \\
\hline & $\begin{array}{l}\text { C-LA } \\
\text { LPLA }\end{array}$ & $\begin{array}{l}12.62 \pm 0.209^{\mathrm{b}} \\
13.92+0.319^{\mathrm{a}}\end{array}$ & $\begin{array}{l}12.68 \pm 0.226 \\
13.99+0.432\end{array}$ & $\begin{array}{l}12.24 \pm 0.124 \\
14.03+0.436\end{array}$ \\
\hline & HPLA & $13.93 \pm 0.272^{\mathrm{a}}$ & $14.10 \pm 0.337$ & $14.37 \pm 0.261$ \\
\hline & $\mathrm{C}-\mathrm{BA}$ & $12.57 \pm 0.378^{\mathrm{b}}$ & $12.71 \pm 0.205$ & $12.51 \pm 0.064$ \\
\hline & LPBA & $14.05 \pm 0.033^{\mathrm{a}}$ & $13.72 \pm 0.228$ & $14.16 \pm 0.032$ \\
\hline & HPBA & $14.29 \pm 0.076^{\mathrm{a}}$ & $14.57 \pm 0.441$ & $14.02 \pm 0.050$ \\
\hline \multicolumn{5}{|l|}{ Fat (\% wt $/ w t)$} \\
\hline & C-LA & $3.45 \pm 0.150$ & $3.40 \pm 0.050$ & $3.43 \pm 0.075$ \\
\hline & LPLA & $3.33 \pm 0.075$ & $3.35 \pm 0.050$ & $3.23 \pm 0.075$ \\
\hline & HPLA & $3.38 \pm 0.025$ & $3.38 \pm 0.025$ & $3.35 \pm 0.050$ \\
\hline & $\mathrm{C}-\mathrm{BA}$ & $3.45 \pm 0.050$ & $3.48 \pm 0.025$ & $3.38 \pm 0.075$ \\
\hline & LPBA & $3.53 \pm 0.025$ & $3.30 \pm 0.100$ & $3.40 \pm 0.100$ \\
\hline & HPBA & $3.45 \pm 0.050$ & $3.43 \pm 0.025$ & $3.50 \pm 0.000$ \\
\hline \multicolumn{5}{|l|}{ Total protein $(\% \mathrm{wt} / \mathrm{wt})$} \\
\hline & LPLA & $3.74 \pm 0.165$ & $3.49 \pm 0.015$ & $3.33 \pm 0.065$ \\
\hline & HPLA & $3.49 \pm 0.110$ & $3.66 \pm 0.200$ & $3.48 \pm 0.005$ \\
\hline & $\mathrm{C}-\mathrm{BA}$ & $3.64 \pm 0.050$ & $3.63 \pm 0.050$ & $3.73 \pm 0.215$ \\
\hline & LPBA & $3.66 \pm 0.330$ & $3.53 \pm 0.065$ & $3.46 \pm 0.165$ \\
\hline & HPBA & $3.67 \pm 0.025$ & $3.52 \pm 0.005$ & $3.46 \pm 0.235$ \\
\hline
\end{tabular}

${ }^{a-c}$ Means in the same column with different lowercase letters show significant differences among samples for each property $(P<0.05)$.

${ }^{\mathrm{A}, \mathrm{B}}$ Means in the same row with different uppercase letters show significant differences across storage period $(P<0.05)$.

${ }^{1} \mathrm{C}-\mathrm{LA}=$ control sample with Lactobacillus acidophilus La-5 (no inulin); LPLA $=$ sample with L. acidophilus La-5 and low-DP inulin; HPLA = sample with L. acidophilus La-5 and high-DP inulin; C-BA = control sample with Bifidobacterium animalis $\mathrm{Bb}-12$ (no inulin); LPBA = sample with B. animalis Bb-12 and low-DP inulin; $\mathrm{HPBA}=$ sample with $B$. animalis $\mathrm{Bb}-12$ and high-DP inulin.

${ }^{2}$ Soxhlet-Henkel degrees. 
Table 3. Viable cell counts ( $\log \mathrm{cfu} / \mathrm{g})$ of fermented milks at 1,15 , and $30 \mathrm{~d}$ of storage (mean $\pm \mathrm{SE} ; \mathrm{n}=2$ )

\begin{tabular}{llccc}
\hline Item & Sample $^{1}$ & $\mathrm{~d} 1$ & $\mathrm{~d} 15$ & $\mathrm{~d} 30$ \\
\hline Lactobacillus acidophilus & C-LA & $8.45 \pm 0.200^{\mathrm{b}}$ & $8.72 \pm 0.135$ & $8.34 \pm 0.170$ \\
& LPLA & $8.74 \pm 0.090^{\mathrm{ab}}$ & $8.98 \pm 0.310$ & $8.69 \pm 0.100$ \\
Bifidobacterium animalis & HPLA & $8.96 \pm 0.170^{\mathrm{a}}$ & $9.07 \pm 0.045$ & $8.94 \pm 0.205$ \\
& C-BA & $7.19 \pm 0.250$ & $7.56 \pm 0.180$ & $7.10 \pm 0.215$ \\
& LPBA & $7.44 \pm 0.335$ & $7.74 \pm 0.055$ & $7.19 \pm 0.175$ \\
& HPBA & $7.25 \pm 0.415$ & $7.63 \pm 0.190$ & $7.03 \pm 0.215$ \\
\hline
\end{tabular}

$\overline{\mathrm{a}, \mathrm{b}}$ Means in the same column with different lowercase letters show significant differences among samples $(P<$ $0.05)$.

${ }^{1} \mathrm{C}-\mathrm{LA}=$ control sample with $L$. acidophilus La-5 (no inulin); LPLA = sample with L. acidophilus La-5 and low-DP inulin; HPLA = sample with $L$. acidophilus La-5 and high-DP inulin; C-BA $=$ control sample with $B$. animalis $\mathrm{Bb}-12$ (no inulin); LPBA = sample with $B$. animalis $\mathrm{Bb}-12$ and low-DP inulin; HPBA = sample with B. animalis $\mathrm{Bb}-12$ and high-DP inulin; $\mathrm{DP}=$ degree of polymerization.

observed from then until d 30. This change is consistent with the decrease and subsequent increase in $\mathrm{pH}$ during storage, which is influenced directly by bacterial activity in fermented milks. The observed $\mathrm{pH}$ decrease during storage is probably related to postacidification caused by continuous production of organic acids derived from the fermentation process of lactose in dairy products by probiotics and the starter culture (Wang et al., 2009). Contrary to our present findings, Konar et al. (2018) showed that the number of viable cells of these strains decreased gradually throughout the storage period of sugar-free probiotic white chocolate. When the viable cell counts of 2 probiotic strains were compared, $L$. acidophilus La-5 had a higher count than did B. animalis Bb-12 during the entire storage period. Similar to our results, Donkor et al. (2007) demonstrated that the viabilities of $L$. acidophilus $\mathrm{L}-10, B$. animalis ssp. lactis B-94, and $L$. casei L-26 were maintained above 8 $\log \mathrm{cfu} / \mathrm{g}$ during the storage of soy milk. Chang et al. (2010) also determined that the viable cell counts of B. breve K-110, Streptococcus thermophilus 3781, and L. acidophilus Q509011 in a soy yogurt immediately after production were $8.75,8.43$, and $8.96 \log \mathrm{cfu} / \mathrm{g}$, respectively, and these counts did not change during 15 $\mathrm{d}$ of refrigerated storage.

Inclusion of inulin into fermented milk enhanced the growth and viability of $L$. acidophilus La-5 and $B$. animalis Bb-12 (Table 3). An increase was observed in both $L$. acidophilus and B. animalis counts with the addition of both low- and high-DP inulin. The increase observed in synbiotic milk produced with high-DP inulin was greater than that produced with low-DP inulin for the strain L. acidophilus La-5. However, the viable cell count for $B$. animalis $\mathrm{Bb}-12$ was determined to be higher when low-DP inulin was used. The viable cell count of $L$. acidophilus showed a significant difference in the samples produced with high-DP inulin compared with the control sample $(P<0.05)$, while $B$. animalis showed no significant difference when low-DP or high-DP inulin was used during production $(P>$ 0.05). Several studies have noted similar results, showing that the majority of Bifidobacterium species are capable of utilizing short-chain inulin to a large extent (Biedrzycka and Bielecka, 2004; Rossi et al., 2005). The increase in the viable cell counts of both strains confirms the synbiotic effect already noted by other researchers (Oliveira et al., 2012; Ehsani et al., 2016). Oliveira et al. (2011) also showed that the incorporation of skim milk with inulin significantly increases the number of probiotic strains in nonfat fermented milk. Mayo et al. (2010) explained this as a result of the fructose released from the hydrolysis of inulin and the stimulating effect of this event on the metabolism of lactic acid bacteria.

Similar results were observed in a study by Ito et al. (2011), where the inulin DP level affected the viability of microorganisms depending on the probiotic strain. In this way, we can conclude that the relationship between DP and viability level is influenced by environmental conditions such as water activity, oxygen level, osmotic pressure, oxidation stability, and the food itself (Konar et al., 2018). These environmental conditions are affected by the addition of inulin and influence the viable cell count of probiotic bacteria.

In contrast, in a study on fermented soy product produced with the addition of $L$. acidophilus and $B$. animalis, supplementation with inulin did not influence probiotic viability during the storage period (Bedani et al., 2013). Similarly, Buriti et al. (2010) did not observe any significant change in the viability of microorganisms during shelf life of refrigerated or frozen milkbased guava mousse supplemented with $L$. acidophilus La-5 and inulin. The differences between those studies and our results could arise from the probiotic strainspecific response (Paseephol and Sherkat, 2009) or from the food matrix.

Lactobacillus and Bifidobacterium spp. are reported to be affected by many factors, such as the probiotic strains, $\mathrm{pH}$, presence of hydrogen peroxide and dis- 
solved oxygen, concentration of lactic and acetic acids, medium buffering capacity, and storage temperature (Donkor et al., 2006). However, the main reasons for loss of probiotic viability are the reduction in $\mathrm{pH}$ of the medium and the accumulation of organic acids arising from growth and fermentation (Shah, 2000b). Therefore, we can conclude that probiotic cell counts and their viability in fermented milk were affected by both $\mathrm{DP}$ values and strain types.

\section{Volatile Flavor Compounds and Organic Acids}

The volatile flavor compounds of fermented milk samples on d 1, 15, and 30 are shown in Table 4. No acetaldehyde was measurable on $\mathrm{d} 1$, but by d 15 , acetaldehyde concentrations had increased in all samples. On d 30, still higher concentrations were obtained in all samples. An interaction was determined between treatments and storage time $(P<0.05)$. The increase in acetaldehyde provided by $B$. animalis was more pronounced than that produced by L. acidophilus. The highest acetaldehyde concentration was observed in the control samples produced with $B$. animalis $\mathrm{Bb}-12$, followed by the same sample with the addition of lowDP inulin and the other control sample produced with L. acidophilus La-5. This increase is not in accordance with previous studies' results, in which the acetaldehyde concentration decreased in yogurt after $21 \mathrm{~d}$ of storage (Laye et al., 1993; Hruskar et al., 1995) due to the conversion of acetaldehyde to ethanol by alcohol dehydrogenase (Chaves et al., 2002). Our results also demonstrate that the addition of inulin had an effect on the acetaldehyde level during storage: higher levels of acetaldehyde were found in the samples produced with

Table 4. Measurements of volatile flavor compounds and organic acids of fermented milk samples at 1, 15, and $30 \mathrm{~d}$ of storage (mean $\pm \mathrm{SE} ; \mathrm{n}=2$ )

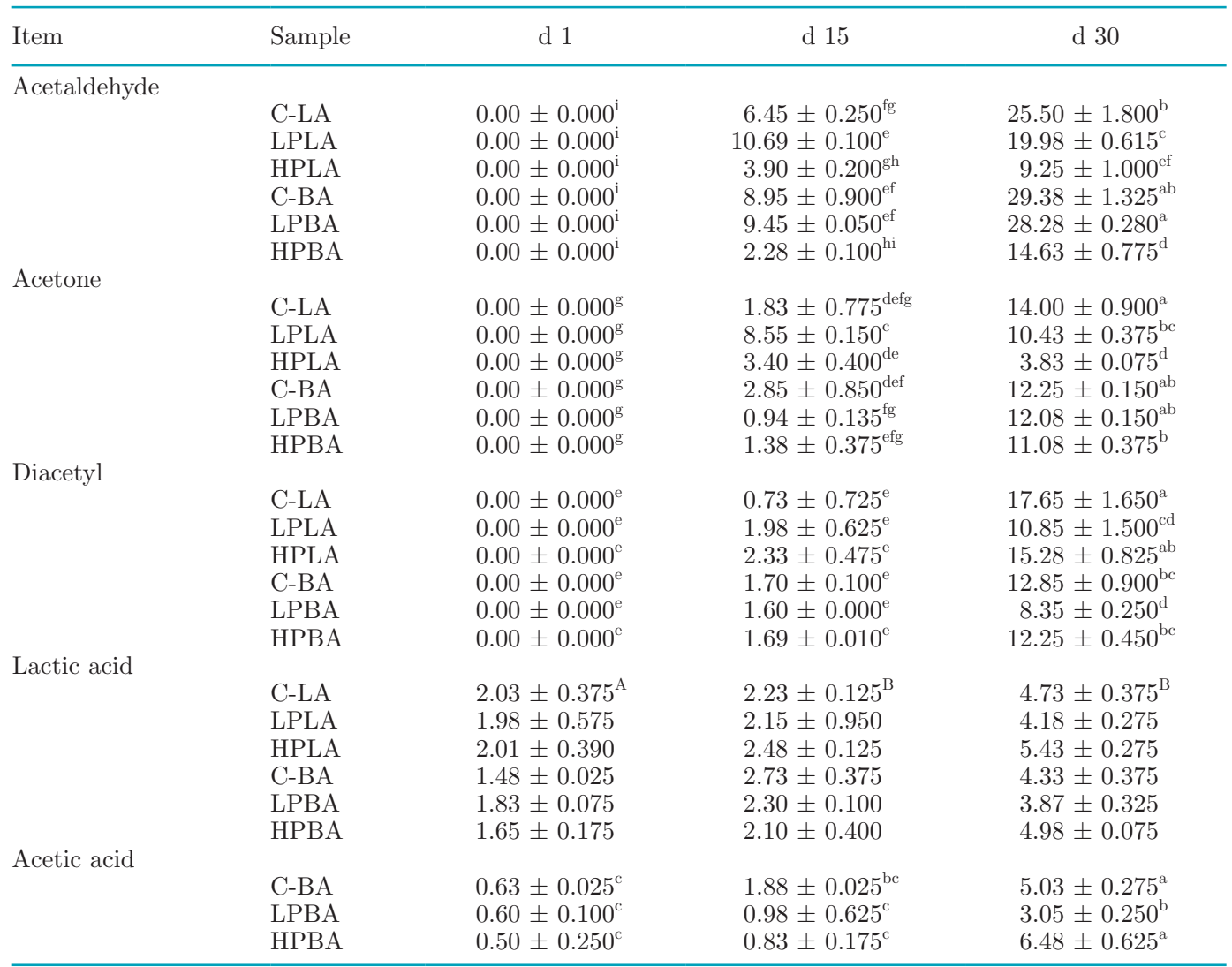

${ }^{\mathrm{a}-\mathrm{i}}$ Means with different lowercase letters show significant differences among samples for each compound $(P<$ $0.05)$.

${ }^{\mathrm{A}, \mathrm{B}}$ Means in the same row with different uppercase letters show significant differences across storage period $(P<0.05)$.

${ }^{1} \mathrm{C}-\mathrm{LA}=$ control sample with Lactobacillus acidophilus La-5 (no inulin); LPLA = sample with L. acidophilus La-5 and low-DP inulin; HPLA = sample with L. acidophilus La-5 and high-DP inulin; C-BA = control sample with Bifidobacterium animalis $\mathrm{Bb}-12$ (no inulin); LPBA = sample with B. animalis Bb-12 and low-DP inulin; $\mathrm{HPBA}=$ sample with $B$. animalis $\mathrm{Bb}-12$ and high-DP inulin; DP = degree of polymerization. 
low-DP inulin than in those produced with high-DP inulin, in all samples.

Acetone and diacetyl concentrations demonstrated similarity to acetaldehyde variation: neither occurred in measurable quantities on the first day of storage. A slight increase was seen in these compounds in all samples by d 15, and a significant increase was recorded on d 30. For both acetone and diacetyl, the highest increases were observed in the control sample produced only with $L$. acidophilus La-5, followed by the control sample produced with $B$. animalis $\mathrm{Bb}-12$. The $B$. animalis synbiot samples showed a higher acetone concentration than samples produced with L. acidophilus. However, the increase in the level of acetone was determined to be higher for the samples fortified with low-DP inulin for both strains. Ethanol was not detected in any sample during the whole storage period. Contrary to our findings, Gyosheva and Rusev (1979), Kang et al. (1988), and Kwak (1995) reported increases in ethanol content during the storage of yogurt.

Table 4 also shows the changes in lactic and acetic acid contents of samples determined by HPLC. The strains did not produce a great deal of organic acids at the beginning of storage, but a significant increase was observed for lactic acid levels for both strains during the second half of the storage period. In general, fermented milk samples containing L. acidophilus La-5 presented higher concentrations of lactic acid across all combinations (from 2.01 to 5.43) than did samples containing B. animalis Bb-12 (from 1.48 to 4.98). The addition of low-DP inulin led to a slightly smaller increase in both acetic and lactic acid concentrations of fermented milks during the whole storage period, whereas high-DP inulin supported the growth of $L$. acidophilus, as seen in Table 3 and, hence, supported a greater increase in the concentration of lactic acid. High-DP inulin showed the largest increase in acetic acid concentration in the second half of the storage period. Even though the concentrations of organic acids in this study were found to be proportional to the counts of probiotics, these results are contrary to some previously reported data about the supporting effects of prebiotics on organic acid concentrations in fermented milk (Batista et al., 2017). This is thought to be dependent on the different metabolic profiles of specific probiotic strains (Batista et al., 2015).

We determined that acetic acid production relied on Bifidobacterium count, because acetic acid is known as an intrinsic metabolite of Bifidobacterium spp. (Karimi et al., 2011) and, accordingly, is produced by the activity of this strain. Some researchers have described $L$. acidophilus as a predominant homofermentative strain producing only lactic acid (Lengkey and Adriani, 2009; Batista et al., 2017). Fewer studies report that some
L. acidophilus strains have the capacity for production of acetic acid (Gomes et al., 2011). As to lactic acid concentration, the control samples of fermented milk were not significantly $(P>0.05)$ different than those of the inulin-added synbiotic samples from d 1 until the end of storage.

\section{Color Measurement}

The results of color measurement of the samples are shown in Table 5. Regarding $\mathrm{L}^{*}$ values, the lightness indicator, no significant difference $(P>0.05)$ was seen between either samples or storage days. However, the red-green color indicator $a^{*}$ was found to be lower in the control samples produced only with probiotic strains than in any of the synbiotic samples throughout the whole storage period. Increase in the $a^{*}$ value of samples supplemented with inulin indicated that the samples are more red. However, we found that lowDP inulin correlated to a greater increase in the $\mathrm{a}^{*}$ measurement than did high-DP inulin or the control samples. We believe that this difference may be due to the fact that the added inulins could have different colors depending on their degree of polymerization or the degree of inulin metabolized by probiotics. The $b^{*}$ values of samples we determined to be high, meaning that the samples were closer to yellowness than to blueness. However, the decrease observed in $b^{*}$ values during storage indicated that yellowness decreased by d 30 of the storage period. Similar to our results, Staffolo et al. (2004) determined that color parameters of yogurt samples produced with different fibers (apple, wheat, bamboo, or inulin) did not show any differences during the storage period except from the apple fibers, which showed a decrease in $\mathrm{L}^{*}$ value. Similarly, in a different study about the influence of long-chain inulin and the probiotic L. paracasei ssp. paracasei on some characteristics of yogurt samples, the color properties of samples did not show any differences based on the added prebiotic or probiotic (Pimentel et al., 2013).

\section{Dynamic Rheological Test}

We found that in all samples the flow behavior index $(n)$ values were in the range of 0.21 to 0.45 (Table 6); values lower than 1 indicate shear-thinning (pseudoplastic) behavior. The consistency index value $(K)$, which can be considered the viscosity value, varied depending on the probiotics and prebiotics used. For high-DP inulin in samples in which L. acidophilus La-5 was used, the consistency index value increased during storage. Similarly, Oliveira et al. (2009b) reported that the addition of 1,2 , and $4 \%$ inulin to fermented milk samples resulted in increases in sample hardness. An- 
Table 5. Color values of fermented milk samples at 1,15 , and $30 \mathrm{~d}$ of storage (mean $\pm \mathrm{SE} ; \mathrm{n}=2$ )

\begin{tabular}{|c|c|c|c|c|}
\hline Item $^{1}$ & Sample $^{2}$ & d 1 & d 15 & d 30 \\
\hline \multicolumn{5}{|c|}{$\mathrm{L}^{*}$ value } \\
\hline & C-LA & $97.19 \pm 0.575$ & $98.9 \pm 0.545$ & $97.45 \pm 1.095$ \\
\hline & LPLA & $97.05 \pm 2.480$ & $98.47 \pm 0.355$ & $97.51 \pm 2.015$ \\
\hline & HPLA & $98.05 \pm 1.950$ & $99.08 \pm 0.530$ & $98.29 \pm 1.715$ \\
\hline & $\mathrm{C}-\mathrm{BA}$ & $97.68 \pm 2.105$ & $98.85 \pm 1.030$ & $97.85 \pm 2.150$ \\
\hline & LPBA & $96.78 \pm 3.050$ & $97.64 \pm 1.400$ & $97.27 \pm 2.730$ \\
\hline * & HPBA & $97.08 \pm 2.640$ & $98.73 \pm 1.270$ & $97.75 \pm 2.245$ \\
\hline d valu & C-LA & $3.03 \pm 0.205$ & $3.97 \pm 0.725$ & $3.60 \pm 0.140$ \\
\hline & LPLA & $4.63 \pm 0.250$ & $4.80 \pm 0.715$ & $4.42 \pm 0.170$ \\
\hline & HPLA & $4.24 \pm 0.585$ & $4.05 \pm 1.180$ & $3.85 \pm 0.230$ \\
\hline & $\mathrm{C}-\mathrm{BA}$ & $3.48 \pm 0.420$ & $3.33 \pm 0.625$ & $3.46 \pm 1.005$ \\
\hline & LPBA & $3.80 \pm 0.410$ & $3.32 \pm 0.235$ & $4.62 \pm 1.150$ \\
\hline & HPBA & $3.58 \pm 0.155$ & $3.52 \pm 0.705$ & $3.80 \pm 1.260$ \\
\hline \multicolumn{5}{|c|}{$\mathrm{b}^{*}$ value } \\
\hline & C-LA & $9.920 \pm 1.645$ & $9.210 \pm 0.840$ & $9.63 \pm 2.280$ \\
\hline & LPLA & $13.00 \pm 2.080$ & $10.32 \pm 2.395$ & $9.99 \pm 3.320$ \\
\hline & HPLA & $11.17 \pm 3.190$ & $9.310 \pm 2.920$ & $8.83 \pm 3.405$ \\
\hline & C-BA & $11.68 \pm 4.020$ & $9.650 \pm 3.495$ & $9.53 \pm 4.060$ \\
\hline & LPBA & $10.74 \pm 5.845$ & $11.54 \pm 3.085$ & $6.58 \pm 0.465$ \\
\hline & HPBA & $10.84 \pm 6.340$ & $11.66 \pm 2.210$ & $6.77 \pm 1.010$ \\
\hline
\end{tabular}

${ }^{1} \mathrm{~L}^{*}=$ lightness; $\mathrm{a}^{*}= \pm$ red-green; $\mathrm{b}^{*}= \pm$ yellow-blue.

${ }^{2} \mathrm{C}-\mathrm{LA}=$ control sample with Lactobacillus acidophilus La-5 (no inulin); LPLA = sample with L. acidophilus La-5 and low-DP inulin; HPLA = sample with L. acidophilus La-5 and high-DP inulin; C-BA = control sample with Bifidobacterium animalis Bb-12 (no inulin); LPBA = sample with B. animalis Bb-12 and low-DP inulin; $\mathrm{HPBA}=$ sample with $B$. animalis $\mathrm{Bb}-12$ and high-DP inulin; $\mathrm{DP}=$ degree of polymerization.

other similar result was obtained in a study examining the flow properties of milk beverages produced with addition of inulin with different DP levels at different ratios. In that study, the viscosity values of samples supplemented with high-DP inulin were found to be higher than those supplemented with low-DP inulin (Villegas and Costell, 2007). The rheology of inulincontaining products depends on inulin crystallization behavior (Bot et al., 2004), and small crystals or crystalline aggregates occur in the high-DP inulin structure in higher quantities (Tárrega et al., 2010), causing it to be more viscous than low-DP inulin. In addition, oligo-, di-, or monosaccharides resulting from the depo- lymerization of inulin, or varying water affinity based on DP values, may affect the rheological properties of the matrix. Heat applications above $80^{\circ} \mathrm{C}$ have been reported to cause inulin hydrolysis (Kim and Wang, 2001); however, hydrolysis of inulin has been found to have no significant effect on the rheological properties of inulin gels (Bot et al., 2004).

When we evaluated control samples, we saw that probiotic strains also correlated with differences in the rheological properties of samples. This effect could vary by the strain of probiotic or by the DP value of inulin. Across the storage period, the consistency index value of the control sample produced with $B$. animalis was

Table 6. Dynamic rheological tests at 1,15 , and $30 \mathrm{~d}$ of storage $(\text { mean } \pm \mathrm{SE} ; \mathrm{n}=2)^{1}$

\begin{tabular}{|c|c|c|c|c|c|c|c|c|c|}
\hline Sample $^{2}$ & \multicolumn{3}{|c|}{ d 1} & \multicolumn{3}{|c|}{ d 15} & \multicolumn{3}{|c|}{ d 30} \\
\hline C-LA & $0.38 \pm 0.039^{\text {efgh }}$ & $0.42 \pm 0.037$ & 0.99 & $0.41 \pm 0.022^{\text {defgh }}$ & $0.45 \pm 0.082$ & 0.98 & $0.60 \pm 0.016^{\text {cdef }}$ & $0.44 \pm 0.000$ & 0.98 \\
\hline HPLA & $0.72 \pm 0.092^{\mathrm{abc}}$ & $0.32 \pm 0.013$ & 0.98 & $0.64 \pm 0.064^{\text {bcde }}$ & $0.29 \pm 0.013$ & 0.97 & $0.93 \pm 0.004^{\mathrm{ab}}$ & $0.25 \pm 0.036$ & 0.93 \\
\hline C-BA & $0.67 \pm 0.007^{\mathrm{abcd}}$ & $0.31 \pm 0.050$ & 0.98 & $0.51 \pm 0.063^{\text {cdefgh }}$ & $0.30 \pm 0.050$ & 0.95 & $0.70 \pm 0.038^{\text {cdefgh }}$ & $0.29 \pm 0.110$ & 0.92 \\
\hline LPBA & $0.34 \pm 0.007^{\mathrm{fgh}}$ & $0.42 \pm 0.059$ & 0.97 & $0.49 \pm 0.041^{\mathrm{h}}$ & $0.31 \pm 0.059$ & 0.99 & $0.53 \pm 0.057^{\mathrm{abc}}$ & $0.24 \pm 0.009$ & 0.98 \\
\hline
\end{tabular}

${ }^{\mathrm{a}-\mathrm{h}}$ Means with different lowercase letters show significant differences among samples $(P<0.05)$.

${ }^{1} K=$ consistency index value; $n=$ flow behavior index.

${ }^{2} \mathrm{C}-\mathrm{LA}=$ control sample with Lactobacillus acidophilus La-5 (no inulin); LPLA = sample with L. acidophilus La-5 and low-DP inulin; HPLA = sample with L. acidophilus La-5 and high-DP inulin; C-BA = control sample with Bifidobacterium animalis Bb-12 (no inulin); LPBA = sample with $B$. animalis $\mathrm{Bb}-12$ and low-DP inulin; $\mathrm{HPBA}=$ sample with $B$. animalis $\mathrm{Bb}-12$ and high-DP inulin; $\mathrm{DP}=$ degree of polymerization. 


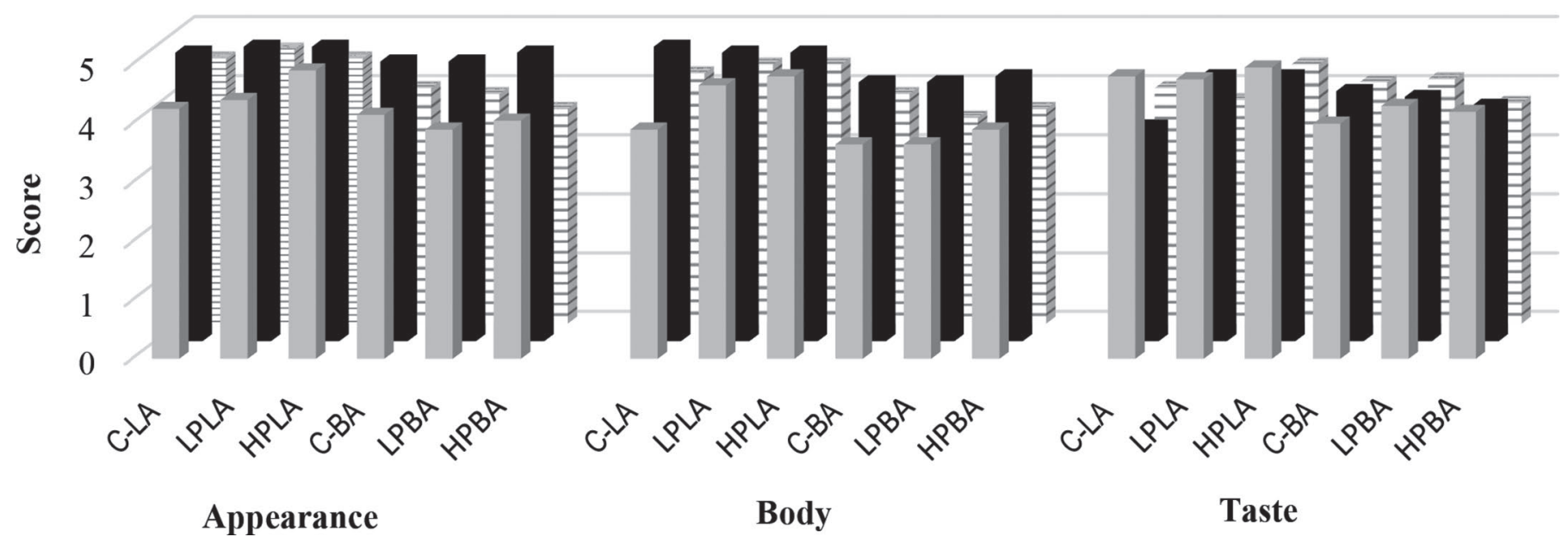

Figure 1. Sensory scores of fermented milks produced using different probiotic bacteria and inulin with different degree of polymerization (DP) values $(\mathrm{n}=2)$. C-LA $=$ control sample with Lactobacillus acidophilus La-5 (no inulin); LPLA = sample with L. acidophilus La-5 and low-DP inulin; HPLA = sample with $L$. acidophilus La-5 and high-DP inulin; C-BA = control sample with Bifidobacterium animalis $\mathrm{Bb}-12$ (no inulin); LPBA = sample with $B$. animalis $\mathrm{Bb}-12$ and low-DP inulin; HPBA = sample with B. animalis Bb-12 and high-DP inulin.

found to be higher than that of the control sample in which L. acidophilus was used. Exopolysaccharide production of Bifidobacterium spp. has been reported to be high (Audy et al., 2010; Prasanna et al., 2014). Furthermore, the viscosity of samples has been determined to increase with an increased exopolysaccharide ratio (Hassan, 2008). Similarly, we found the consistency index values of the control samples supplemented with $B$. animalis to be higher than those of the L. acidophilus control samples. However, inulin in samples produced with $B$. animalis correlated with lower viscosity. This demonstrated that prebiotic addition adversely affects exopolysaccharide production. Other studies exploring the rheological properties of dairy products fortified with inulin also reported increases in the apparent viscosities of products, such as probiotic ice cream produced by the incorporation of inulin at a ratio of $4 \%$ (Akalin and Erişir, 2008) and in yog-ice cream produced with the addition of 5, 7, and 9\% inulin (El-Nagar et al., 2002).

We found that consistency index values tended to increase in all samples by the end of storage. Samples containing high-DP inulin showed the greatest increase. Similarly, in a study in which rheological properties of a custard dessert enriched with inulins of different degrees of polymerization were researched for $7 \mathrm{~d}$, a greater increase was determined in samples containing long-chain inulin during storage (Tárrega et al., 2011). In a recent study, Konar et al. (2018) also reported that the addition of inulin and probiotic strains affected the rheological attributes such as plastic viscosity and yield value in sugar-free white chocolate.

\section{Sensory Evaluation}

As Figure 1 shows, we found variation in sensory properties of the fermented milk samples across the entire storage period. An increase in sensory acceptance was observed over $15 \mathrm{~d}$ of refrigerated storage; however, this preference decreased with prolonged storage until d 30 of storage. The samples produced by L. acidophilus La-5 were preferred to samples produced with $B$. animalis $\mathrm{Bb}-12$, with regard to appearance, body, and taste. Similarly, the synbiotic products produced with L. acidophilus La-5 and inulin were preferred to the probiotic product that used only L. acidophilus La-5, with regard to appearance, body, and taste. However, for the strain of $B$. animalis Bb-12, the probiotic product was preferred by the sensory panel over the synbiotic ones with regard to the same sensory aspects. When polymerization degree was compared, high-DP inulin products had higher scores for appearance and body in the fermented milk samples, whereas the lowDP inulin products were more preferred in terms of the taste of samples. Similar to our results, inulin has been determined to increase the sense of creaminess in ice cream when used as a fat replacer (Akbari et al., 2016).

\section{CONCLUSIONS}

The present study found that inulin has a stimulating effect on the growth and viability of both probiotics, independently of the polymerization degree. The use of either high-DP or low-DP inulin resulted in higher 
viscosity in the fermented milks during the storage period for both probiotic strains, although the increase observed in the product supplemented with high-DP inulin was greater than that of the product supplemented with low-DP inulin. Moreover, addition of either type of inulin significantly influenced the acidification kinetics of probiotic strains in products. The concentrations of volatile compounds of acetaldehyde, acetone, and diacetyl were determined to be lower in synbiotic products supplemented with either type of inulin, compared with the unsupplemented probiotic products. However, high-DP inulin demonstrated a more pronounced effect on the decrease of acetaldehyde and acetone during storage and led to an increase in lactic and acetic acids in the products, compared with low-DP inulin. The synbiotic products were preferred to the probiotic products by the sensory panel in terms of appearance, body, and taste. Because inulin with different polymerization degrees has different effects on fermented milk, the type of inulin to be used during production should be decided according to the desired product characteristics. Furthermore, inulin not only improved the physical and sensory properties of fermented milk but also supported the growth and viability of probiotic bacteria. Therefore, this product can be introduced as a good vehicle for the production of functional dairy products. Additionally, to produce an innovative synbiotic fermented dairy product, we recommend evaluating the probiotic strain and the DP values of inulin simultaneously as part of process development and the reformulation of the product.

\section{ACKNOWLEDGMENTS}

We thank Nevzat Konar (Siirt University, Faculty of Engineering and Architecture, Department of Food Engineering, Siirt, Turkey) for his critical reading of this manuscript.

\section{REFERENCES}

Akalın, A. S., and D. Erişir. 2008. Effects of inulin and oligofructose on the rheological characteristics and probiotic culture survival in low-fat probiotic ice cream. J. Food Sci. 73:M184-M188.

Akbari, M., M. H. Eskandari, M. Niakosari, and A. Bedeltavana. 2016. The effect of inulin on the physicochemical properties and sensory attributes of low-fat ice cream. Int. Dairy J. 57:52-55.

Akin, Z., and T. Ozcan. 2017. Functional properties of fermented milk produced with plant proteins. Lebensm. Wiss. Technol. 86:25-30.

AOAC International. 2006. Official Methods of Analysis. 18th ed. AOAC International, Gaithersburg, MD.

Aryana, K. J., S. Plauche, R. M. Rao, P. Mcgrew, and N. P. Shah. 2007. Fat-free plain yoghurt manufactured with inulins of various chain lengths and Lactobacillus acidophilus. J. Food Sci. 72:M79M84.

Audy, J., S. Labrie, D. Roy, and G. LaPointe. 2010. Sugar source modulates exopolysaccharide biosynthesis in Bifidobacterium longum ssp. longum CRC 002. Microbiology 156:653-664.
Batista, A. L. D., R. Silva, L. P. Cappato, C. N. Almada, R. K. A. Garcia, M. C. Silva, R. S. L. Raices, D. B. Arellano, A. S. Sant'Ana, C. A. Conte Junior, M. Q. Freitas, and A. G. Cruz. 2015. Quality parameters of probiotic yogurt added to glucose oxidase compared to commercial products through microbiological, physical-chemical and metabolic activity analyses. Food Res. Int. 77:627-635.

Batista, A. L. D., R. Silva, L. P. Cappato, M. V. S. Ferreira, K. O. Nascimento, M. Schmiele, E. A. Esmerino, C. F. Balthazar, H. L. A. Silva, J. Moraes, T. C. Pimentel, M. Q. Freitas, R. S. L. Raices, and M. C. Silva. 2017. Developing a synbiotic fermented milk using probiotic bacteria and organic green banana flour. J. Funct. Foods 38:242-250.

Bedani, R., E. A. Rossi, and S. M. I. Saad. 2013. Impact of inulin and okara on Lactobacillus acidophilus La-5 and Bifidobacterium animalis $\mathrm{Bb}-12$ viability in a fermented soy product and probiotic survival under in vitro simulated gastrointestinal conditions. Food Microbiol. 34:382-389.

Biedrzycka, E., and M. Bielecka. 2004. Prebiotic effectiveness of fructans of different degrees of polymerization. Trends Food Sci. Technol. 15:170-175.

Bodyfelt, F. W., J. Tobias, and G. M. Trout. 1988. The Sensory Evaluation of Dairy Products. Van Nostrand Reinhold, New York, NY.

Bogovič Matijašić, B., T. Obermajer, L. Lipoglavšek, T. Sernel, I. Locatelli, M. Kos, A. Šmid, and I. Rogelj. 2016. Effects of synbiotic fermented milk containing Lactobacillus acidophilus La-5 and Bifidobacterium animalis ssp. lactis BB-12 on the fecal microbiota of adults with irritable bowel syndrome: A randomized double-blind, placebo-controlled trial. J. Dairy Sci. 99:5008-5021.

Bot, A., U. Erle, R. Vreeker, and W. G. M. Agterof. 2004. Influence of crystallisation conditions on the large deformation rheology of inulin gels. Food Hydrocoll. 18:547-556.

Boylston, T. D., C. G. Vinderola, H. B. Ghoddusi, and J. A. Reinheimer. 2004. Incorporation of bifidobacteria into cheeses: Challenges and rewards. Int. Dairy J. 14:375-387.

Bradley, R. L. J., E. J. Arnold, D. M. Barbano, R. G. Semerad, D. E. Smith, and B. K. Vines. 1993. Chemical and physical methods. Pages 433-531 in Standard Methods for the Examination of Dairy Products. R. T. Marshall, ed. American Public Health Association, Washington, DC.

Buriti, F. C. A., I. A. Castro, and S. M. I. Saad. 2010. Viability of Lactobacillus acidophilus in synbiotic guava mousses and its survival under in vitro simulated gastrointestinal conditions. Int. J. Food Microbiol. 137:121-129.

Cardarelli, H. R., L. C. Aragon-Alegro, J. Alegro, I. A. de Castro, and S. M. Saad. 2008. Effect of inulin and Lactobacillus paracasei on sensory and instrumental texture properties of functional chocolate mousse. J. Sci. Food Agric. 88:1318-1324.

Chang, S. Y., D. H. Kim, and M. J. Han. 2010. Physicochemical and sensory characteristics of soy yogurt fermented with Bifidobacterium breve K-110, Streptococcus thermophilus 3781 or Lactobacillus acidophilus Q509011. Food Sci. Biotechnol. 19:107-113.

Chaves, A. C. S. D., M. Fernandez, A. L. S. Lerayer, I. Mierau, M. Kleerebezem, and J. Hugenholtz. 2002. Metabolic engineering of acetaldehyde production by Streptococcus thermophilus. Appl. Environ. Microbiol. 68:5656-5662.

Chaves, K. S., and M. L. Gigante. 2016. Prato cheese as suitable carrier for Lactobacillus acidophilus La5 and Bifidobacterium Bb12. Int. Dairy J. 52:10-18.

Donkor, O. N., A. Henriksson, T. Vasiljevic, and N. P. Shah. 2006. Effect of acidification on the activity of probiotics in yoghurt during cold storage. Int. Dairy J. 16:1181-1189.

Donkor, O. N., S. L. I. Nilmini, P. Stolic, T. Vasiljevic, and N. P. Shah. 2007. Survival and activity of selected probiotic organisms in settype yoghurt during cold storage. Int. Dairy J. 17:657-665.

Ehsani, A., E. K. Banihabib, M. Hashemi, M. Saravani, and E. Yarahmadi. 2016. Evaluation of various properties of symbiotic yoghurt of buffalo milk. J Food Process. Pres. 40:1466-1473.

El-Nagar, G., G. Clowes, C. M. Tudorica, V. Kuri, and C. S. Brennan. 2002. Rheological quality and stability of yog-ice cream with added inulin. Int. J. Dairy Technol. 55:89-93. 
FAO/WHO. 2006. Food and Agriculture Organization of the United Nations; World Health Organization. FAO food and nutrition paper 85. Probiotics in food: Health and nutritional properties and guidelines for evaluation. FAO/WHO, Rome, Italy.

FAO/AGNS. 2007. Food and Agriculture Organization of the United Nations; Food Quality and Standards Service. FAO Technical Meeting on Prebiotics. FAO/AGNS, Rome, Italy.

Gibson, G. R., and M. B. Roberfroid. 1995. Dietary modulation of the human colonic microbiota: Introducing the concept of prebiotics. J. Nutr. 125:1401-1412.

Gibson, G. R., K. P. Scott, R. A. Rastall, K. M. Tuohy, A. Hotchkiss, A. Dubert-Ferrandon, M. Gareau, E. F. Murphy, D. Saulnier, G. Loh, S. Macfarlane, N. Delzenne, Y. Ringel, G. Kozianowski, R. Dickman, I. Lenoir-Wijnkoop, C. Walker, and R. Buddington. 2010. Dietary prebiotics: Current status and new definition. Food Sci. Technol. Bull. Funct. Foods. 7:1-19.

Gomes, A. A., S. P. Braga, A. G. Cruz, R. S. Cadena, P. C. Lollo, and C. C. Carvalho. 2011. Effect of the inoculation level of Lactobacillus acidophilus in probiotic cheese on the physicochemical features and sensory performance compared with commercial cheeses. J. Dairy Sci. 94:4777-4786.

Guimarães, J. T., E. K. Silva, A. L. R. Costa, R. L. Cunha, M. Q. Freitas, M. A. A. Meireles, and A. G. Cruz. 2018. Manufacturing a prebiotic whey beverage exploring the influence of degree of inulin polymerization. Food Hydrocoll. 77:787-795.

Gyosheva, B. H., and P. Rusev. 1979. Gas chromatography and spectral method application for the study of the Bulgarian yoghurt flavour. Nahrung 23:385-392.

Hassan, A. N. 2008. ADSA Foundation Scholar Award: Possibilities and challenges of exopolysaccharide-producing lactic cultures in dairy foods. J. Dairy Sci. 91:1282-1298.

Hruskar, M., N. Vahcic, and M. Ritz. 1995. Aroma profiles and sensory evaluation of yogurt during storage. Mljekarstvo 45:175-190.

IDF. 1993. Determination of nitrogen content. Standard no. 20B. International Dairy Federation, Brussels, Belgium.

Ito, H., N. Takemura, K. Sonoyama, H. Kawagishi, D. L. Topping, M. A. Conlon, and T. Morita. 2011. Degree of polymerization of inulin-type fructans differentially affects number of lactic acid bacteria, intestinal immune functions, and immunoglobulin A secretion in the rat cecum. J. Agric. Food Chem. 59:5771-5778.

Kang, Y. J., J. F. Frank, and D. A. Lillard. 1988. Gas chromatographic detection of yogurt flavor compounds and changes during refrigerated storage. Cult. Dairy Products Int. 23:6-9.

Karimi, R., A. M. Mortazavian, and A. G. Cruz. 2011. Viability of probiotic microorganisms in cheese during production and storage: A review. Dairy Sci. Technol. 91:283-308.

Kim, G. Y., and S. S. Wang. 2001. Kinetic study of thermally induced inulin gel. J. Food Sci. 66:991-997.

Kip, P., D. Meyerb, and R. H. Jellema. 2006. Inulins improve sensoric and textural properties of low-fat yoghurts. Int. Dairy J. 16:1098-1103.

Konar, N., I. Palabiyik, O. S. Toker, D. Genc Polat, E. Kelleci, H. R. Pirouzian, A. Akcicek, and O. Sagdic. 2018. Conventional and sugar-free probiotic white chocolate: Effect of inulin DP on various quality properties and viability of probiotics. J. Funct. Foods 43:206-213.

Konar, N., I. Palabiyik, O. S. Toker, D. Genc Polat, S. Sener, A. Akcicek, and O. Sagdic. 2017. Effect of inulin DP on various properties of sugar-free dark chocolates containing Lactobacillus paracasei and Lactobacillus acidophilus. Int. J. Food Eng. 13. https://doi .org/10.1515/ijfe-2017-0045.

Kwak, H. S. 1995. Effect of volatile flavor compound on yogurt during refrigerated storage. Korean J. Food Sci. Technol. 27:939-943.

Laye, I., D. Karleskind, and C. V. Morr. 1993. Chemical, microbiological and sensory properties of plain nonfat yogurt. J. Food Sci. 58:991-995.

Lengkey, H. A. W., and L. Adriani. 2009. Effects of milk fermented with Lactobacillus acidophilus and Bifidobacterium spp., on lactic acid and acetic acid content and on Staphylococcus aureus and Pseudomonas aeruginosa. Biotechnol. Anim. Husb. 25:719-724.
Luo, D., Y. Li, B. Xu, G. Ren, P. Li, X. Li, S. Han, and J. Liu. 2017a. Effects of inulin with different degree of polymerization on gelatinization and retrogradation of wheat starch. Food Chem. 229:35-43.

Luo, D., X. Liang, B. Xu, X. Kou, P. Li, S. Han, J. Liu, and L. Zhou. 2017b. Effect of inulin with different degree of polymerization on plain wheat dough rheology and the quality of steamed bread. J. Cereal Sci. 75:205-212.

Mayo, B., T. Aleksandrzak-Piekarczyk, M. Fernandez, M. Kowalczyk, P. Alvarez-Martin, and J. Bardowski. 2010. Updates in the metabolism of lactic acid bacteria. Pages 3-33 in Biotechnology of Lactic Acid Bacteria: Novel Applications. F. Mozzi, R. R. Raya, and G. M. Vignolo, ed. Wiley-Blackwell, Hoboken, NJ.

Meyer, D., S. Bayarri, A. Tárrega, and E. Costell. 2011. Inulin as texture modifier in dairy products. Food Hydrocoll. 25:1881-1890.

Mueller, M., H. Viernstein, R. Loeppert, and W. Praznik. 2015. Prebiotic effect of fructans with different structure and polymerization degree. Pages 22-23 in International Scientific Conference on Probiotics and Prebiotics. IPC2015, Budapest, Hungary.

Oberg, C. J., L. V. Moyes, M. J. Domek, C. Brothersen, and D. J. McMahon. 2011. Survival of probiotic adjunct cultures in cheese and challenges in their enumeration using selective media. J. Dairy Sci. 94:2220-2230.

Oliveira, D., L. Vidal, G. Ares, E. H. M. Walter, A. Rosenthal, and R. Deliza. 2017. Sensory, microbiological and physicochemical screening of probiotic cultures for the development of non-fermented probiotic milk. Lebensm. Wiss. Technol. 79:234-241.

Oliveira, R. P. S., A. C. R. Florence, R. C. Silva, P. Perego, A. Converti, L. A. Gioielli, and M. N. Oliveira. 2009a. Effect of different prebiotics on the fermentation kinetics, probiotic survival and fatty acids profiles in nonfat symbiotic fermented milk. Int. J. Food Microbiol. 128:467-472.

Oliveira, R. P. S., P. Perego, A. Converti, and M. N. de Oliveira. 2009b. The effect of inulin as a prebiotic on the production of probiotic fibre-enriched fermented milk. Int. J. Dairy Technol. 62:195-203.

Oliveira, R. P. S., P. Perego, M. N. de Oliveira, and A. Converti. 2012 Growth, organic acids profile and sugar metabolism of Bifidobacterium lactis in co-culture with Streptococcus thermophilus: The inulin effect. Food Res. Int. 48:21-27.

Oliveira, R. P. S., P. Perego, M. N. Oliveira, and A. Converti. 2011 Effect of inulin as a prebiotic to improve growth and counts of a probiotic cocktail in fermented skim milk. Lebensm. Wiss. Technol. 44:520-523.

Ong, L., A. Henriksson, and N. P. Shah. 2006. Development of probiotic Cheddar cheese containing Lactobacillus acidophilus, Lb. casei, Lb. paracasei and Bifidobacterium spp. and the influence of these bacteria on proteolytic patterns and production of organic acid. Int. Dairy J. 16:446-456.

Ong, L., A. Henriksson, and N. P. Shah. 2007. Proteolytic pattern and organic acid profiles of probiotic Cheddar cheese as influenced by probiotic strains of Lactobacillus acidophilus, Lb. paracasei, Lb. casei or Bifidobacterium sp. Int. Dairy J. 17:67-78.

Pandey, A., G. Du, M. Á. Sanromán, C. R. Soccol, and C. G. Dussap. 2017. Current developments in biotechnology and bioengineering: Food and beverages industry. Elsevier, Amsterdam, the Netherlands.

Paseephol, T., and F. Sherkat. 2009. Probiotic stability of yoghurts containing Jerusalem artichoke inulins during refrigerated storage. J. Funct. Foods 1:311-318.

Paseephol, T., D. M. Small, and F. Sherkat. 2008. Rheological and texture of set yogurt as affected by inulin addition. J. Texture Stud. 39:617-634.

Pimentel, T. C., A. G. Cruz, and S. H. Prudencio. 2013. Short communication: Influence of long-chain inulin and Lactobacillus paracasei subspecies paracasei on the sensory profile and acceptance of a traditional yogurt. J. Dairy Sci. 96:6233-6241.

Prasanna, P. H. P., A. S. Grandison, and D. Charalampopoulos. 2014 Bifidobacteria in milk products: An overview of physiological and biochemical properties, exopolysaccharide production, selection criteria of milk products and health benefits. Food Res. Int. $55: 247-262$. 
Rezaei, R., M. Khomeiri, M. Aalami, and M. Kashaninejad. 2014. Effect of inulin on the physicochemical properties, flow behavior and probiotic survival of frozen yogurt. J. Food Sci. Technol. 51:2809-2814.

Rossi, M., C. Corradini, A. Amaretti, M. Nicolini, A. Pompei, S. Zanoni, and D. Matteuzzi. 2005. Fermentation of fructooligosaccharides and inulin by bifidobacteria: A comparative study of pure and fecal cultures. Appl. Environ. Microbiol. 71:6150-6158.

Saxelin, M., S. Tynkkynen, T. Mattila-Sandholm, and W. M. de Vos, 2005. Probiotic and other functional microbes: From markets to mechanisms. Curr. Opin. Biotechnol. 16:204-211.

Shah, C., N. Mokashe, and V. Mishra. 2016. Preparation, characterization and in vitro antioxidative potential of synbiotic fermented dairy products. J. Food Sci. Technol. 53:1984-1992.

Shah, N. P. 2000a. Some beneficial effects of probiotic bacteria. Biosci. Microflora 19:99-106.

Shah, N. P. 2000b. Probiotic bacteria: Selective enumeration and survival in dairy foods. J. Dairy Sci. 83:894-907.

Shah, N. P., and R. R. Ravula. 2000. Influence of water activity on fermentation, organic acids production and viability of yoghurt and probiotic bacteria. Aust. J. Dairy Technol. 55:127-131.

Shoaib, M., A. Shehzad, M. Omar, A. Rakha, H. Raza, H. R. Sharif, and S. Niazi. 2016. Inulin: Properties, health benefits and food applications. Carbohydr. Polym. 147:444-454.

Silva, E. K., M. T. M. Gomes, M. D. Hubinger, R. L. Cunha, and M. A. A. Meireles. 2015. Ultrasound-assisted formation of annat- to seed oil emulsions stabilized by biopolymers. Food Hydrocoll. 47:1-13.

Soukoulis, C., D. Lebesi, and C. Tzia. 2009. Enrichment of ice cream with dietary fibre: Effects on rheological properties, ice crystallisation and glass transition phenomena. Food Chem. 115:665-667.

Staffolo, M. D., N. Bertola, M. Martino, and A. Bevilacqua. 2004. Influence of dietary fiber addition on sensory and rheological properties of yogurt. Int. Dairy J. 14:263-268.

Tárrega, A., A. Rocafull, and E. Costell. 2010. Effect of blends of short and long-chain inulin on the rheological and sensory properties of prebiotic low-fat custards. Lebensm. Wiss. Technol. 43:556-562. https://doi.org/10.1016/j.lwt.2009.10.002.

Tárrega, A., J. D. Torres, and E. Costell. 2011. Influence of the chainlength distribution of inulin on the rheology and microstructure of prebiotic dairy desserts. J. Food Eng. 104:356-363.

Ulberth, F. 1991. Headspace gas chromatographic estimation of some yogurt volatiles. J. Assoc. Off. Anal. Chem. 74:630-643.

Villegas, B., and E. Costell. 2007. Flow behaviour of inulin-milk beverages. Influence of inulin average chain length and of milk fat content. Int. Dairy J. 17:776-781.

Wang, J., Z. Guo, Q. Zhang, L. Yan, W. Chen, X. M. Liu, and H. P. Zhang. 2009. Fermentation characteristics and transit tolerance of probiotic Lactobacillus casei Zhang in soymilk and bovine milk during storage. J. Dairy Sci. 92:2468-2476. 